\title{
Correction to: Structural and Functional Aspects of Muscarinic Receptors in Correlation with Anticholinergic Drugs
}

Pramod Kumar Singh, Rajendra Nath, Ram Naraian, and Manish Kumar Gupta

\section{Correction to: \\ Chapter 13 in: D. B. Singh, T. Tripathi (eds.), Frontiers in Protein Structure, Function, and Dynamics, https://doi.org/10.1007/978-981-15-5530-5_13}

The book was inadvertently published with an incorrect affiliation of the authors Ram Naraian and Manish Kumar Gupta in Chapter 13 as Department of Biochemistry, Veer Bahadur Singh Purvanchal University, Jaunpur, Uttar Pradesh, India. The affiliation has been corrected as Department of Biotechnology, Veer Bahadur Singh Purvanchal University, Jaunpur, Uttar Pradesh, India. 